\title{
СИНТЕЗ МЕТАНОЛА ДЛЯ ОПРЕДЕЛЕНИЯ ЕСТЕСТВЕННОГО РАДИОУГЛЕРОДА СЦИНТИЛЛЯЦИОННЫМ МЕТОДОМ
}

\author{
А. ЛИИВА, Э. иЛЬВЕС
}

Основным фактором, ограничивающим применение сцинтилляционного метода для определения возраста углеродсодержащих материалов, является сложность химических синтезов, необходимых для превращения материала пробы в форму, пригодную для счета.

Синтез метанола, используемый для этой цели в геобиохимической лаборатории Института зоологии и ботаники АН ЭССР (Liiva, 1959; Liiva, Soovik, 1961), достаточно прост и не требует сложной аппаратуры. Применяя метанол в составе сцинтиллятора, можно датировать образцы возрастом до 30000 лет, что вполне достаточно для решаемых лабораторией проблем (палеобиологические, геологические и археологические вопросы Прибалтики). Далее следует отметить, что диэтилкарбитол и бутилкарбитол, применяемые в ходе синтеза зарубежными авторами (Nystrom et al., 1948; Cox et al., 1950; Pringle et al., 1955; Delaney, McAulay, 1959), мы заменили соответственно н-дибутиловым эфиром и бензиловым спиртом - реактивами более доступными и дешевыми.

Синтез метанола из углерода исследуемого образца включает в себе следующие химические операции: 1) предварительная обработка эбразца; 2) выделение из него двуокиси углерода; 3) дополнительная очистка выделенной двуокиси углерода вакуумной сублимацией; 4) абсорбция и восстановление двуокиси углерода в литий-алюминий метилат; 5) алкоголиз полученного литий-алюминий метилата; 6) выделение метанола из реакционной смеси и очи'стка его.

Основные реакции, описываюшие синтез, следующие:

$$
\begin{gathered}
4 \mathrm{CO}_{2}+3 \mathrm{LiAlH}_{4} \longrightarrow 2 \mathrm{LiAlO}_{2}+\mathrm{LiAl}\left(\mathrm{OCH}_{3}\right)_{4} \\
\mathrm{LiAl}\left(\mathrm{OCH}_{3}\right)_{4}+4 \mathrm{C}_{6} \mathrm{H}_{5} \mathrm{CH}_{2} \mathrm{OH} \stackrel{\text { to }}{\longrightarrow} \mathrm{LiAl}\left(\mathrm{OC}_{6} \mathrm{H}_{5} \mathrm{CH}_{2}\right)_{4}+4 \mathrm{CH}_{3} \mathrm{OH}
\end{gathered}
$$

Ниже остановимся подробнее на отдельных этапах синтеза.

Предварительная обработка образца. Органические образцы (уголь, древесина, торф и т. п.) очищают от посторонних включений механическим путем, измельчают и' кипятят в течение 15 минут с $2 \%$-ным раствором $\mathrm{NaOH}$ для удаления гуминовых кислот. Затем образцы промывают дистиллированной водой, кипятят 30 минут с 5\%-ным раствором $\mathrm{HCl}$ для разрушения возможных карбонатных включений, снова промывают дистиллированной водой и высушивают при $110^{\circ} \mathrm{C}$. 
Образеці, обработанный вышеуказанным способом, обугливают путем сухой перегонки.

Карбонатные образцы очищают от постторонних включений и измельчают.

Выделение двуокиси углерода из образца и ее предварительная .очистка осуществляется в установке, изображенной.на фиг. 1 *.

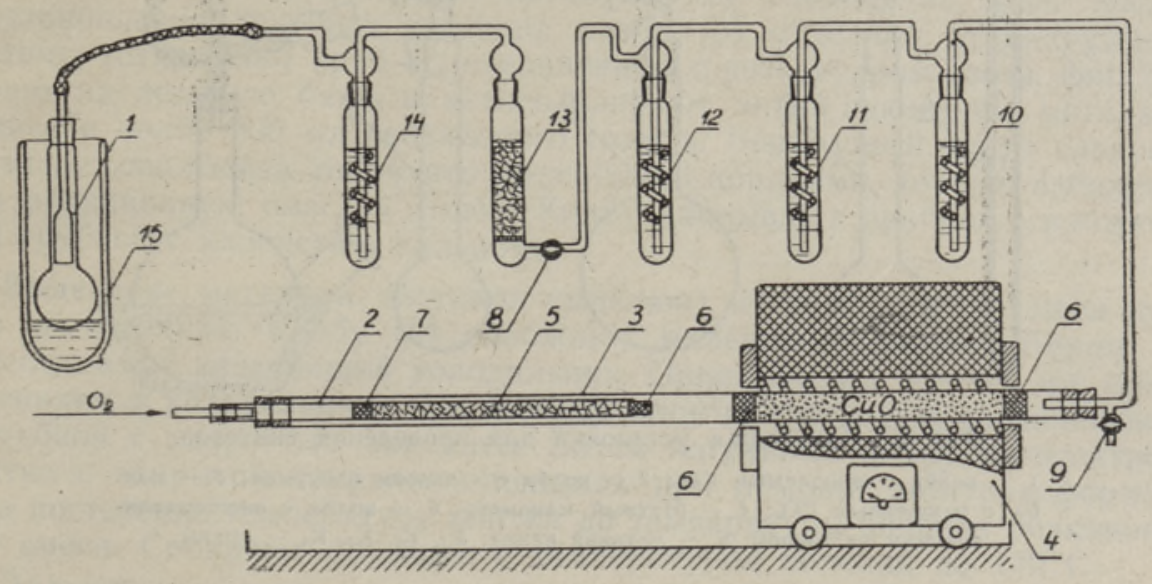

Фиг. 1. Установка для сжигания обугленных образцов до $\mathrm{CO}_{2}$

1 - колба-нриемннк для $\mathrm{CO}_{2} ; 2$ - кварцевая трубка Ф 22 мм; 3 - кварцевая трубка Ф 30 мм; 4- подвижная электрическая печь; 5 - обугленный образец; 6 - пробки нз $\mathrm{Ag}$ сетки; 7 - пробка из $\mathrm{Cu}$ сетки; $8,9-$ краны; 10 - промывная склянка с $\mathrm{CrO}_{3}$ в $\mathrm{H}_{2} \mathrm{SO}_{4} ; 11,12$ - промывные склянки с $\mathrm{H}_{2} \mathrm{O} ; 13$ - колонка с $\mathrm{CaCl}_{2} ; 14$ - промывная склянка с концентрированной $\mathrm{H}_{2} \mathrm{SO}_{4} ; 15$ - Дюар с жндким воздухом.

10-12 г обугленного образца (5) помещают в кварцевую трубку (2), доводят температуру подвижной электрической. печи (4) до $700^{\circ} \mathrm{C}$ и пронускают из баллона через систему в течение 30 минут очищенный от двуокиси углерода кислород. Затем, не прекращая тока кислорода, ставят под колбу (1) Дюар с жидким кислородом, передвигают печь на образец и повышают температуру печи до воспламенения образца $\left(750-850^{\circ} \mathrm{C}\right)$. После этого печь передвигается в первоначальное положение, т. е. на окись меди, и температура печи снижается до $700^{\circ} \mathrm{C}$. Температурный режи'м печи регулируется специальным автотрансформатором, скорость сжигания образца - током кислорода, поступающим в зону горения.

Выделенная двуокись углерода проходит систему очистки, которая собрана на шлифах из промывных склянок типа Вальтера. Первая склянка (10) содержит раствор хромовой окиси в концентрированной серной кислоте, две следующие $(11,12)$ - дистиллированную воду, освобожденную от двуокиси углерода. Следует колонка (13) с хлористым кальцием и промывная склянка (14) с концентрированной серной кислотой. Очищенную таким образом двуокись углерода собирают путем замораживания в колбе (1) и взвешивают.

Из карбонатных образцов выделяют двуокись углерода при помощи соляной кислоты $(1: 1)$.

* Aппаратура для синтеза изготовлена в мастерской геобиохимической лаборатории Института зоологии и ботаники АН ЭССР,

3* ENSV TA Toimetised T-4 62 
Дополнительная очистка двуокиси углерода вакуумной сублимацией. Для выделения возможных включений замороженную двуокись углерода очищают дополнительно путем вакуумной сублимации в установке, изображенной на фиг. 2.

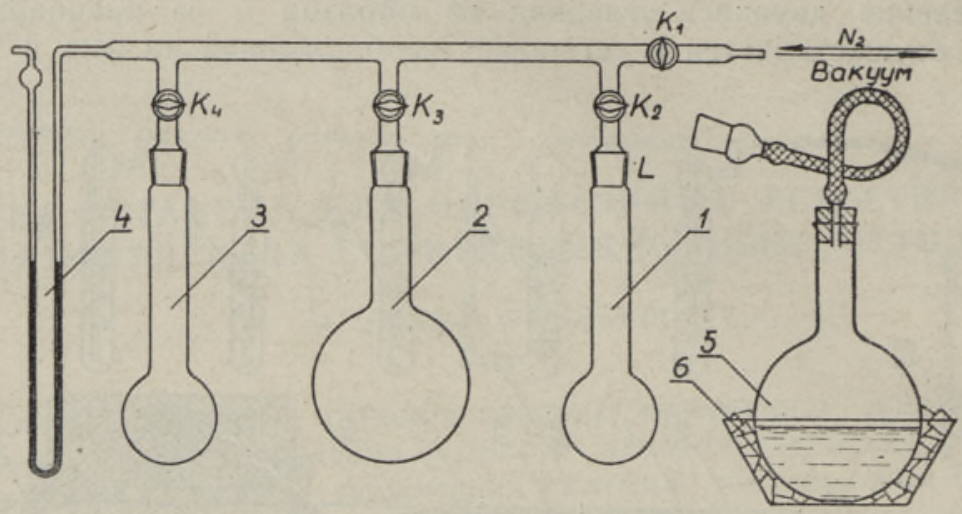

Фиг. 2. Вакуумная установка для проведения синтезов.

1 - колба с очищаемым $\mathrm{CO}_{2} ; 2$ - колба с жзапасом вакуума»; 3 - кол-

ба с очнщенным $\mathrm{CO}_{2}: 4$ - ртутный манометр; 5 - колба с восстанавли-

вающим раствором; 6 - ледяная ванна; $\mathrm{K}_{1}, \mathrm{~K}_{2}, \mathrm{~K}_{3}, \mathrm{~K}_{4}-$ краны.

Из системы откачивают воздух вакуумным насосом (BH-461) при открытых кранах $\mathrm{K}_{1}, \mathrm{~K}_{3}, \mathrm{~K}_{4}$; кран $\mathrm{K}_{2}$ закрыт. Не включая насос, закрывают краны $\mathrm{K}_{3}, \mathrm{~K}_{4}$, на шлиф $\mathrm{L}$ надевают колбу (1) (не удаляя из-под колбы Дюар. См. фиг. 1) и медленно открывают кран $\mathrm{K}_{2}$. При этом давление в системе несколько повышается, но вскоре достигает своего прежнего значения. После этого закрывают кран $\mathrm{K}_{1}$, выключают вакуумный насос, переставляют Дюар с жидким кислородом и'з-под колбы (1) под колбу (3) и открывают кран $\mathrm{K}_{4}$. Давление в системе возрастает и достигает значения, соответствующего сублимационному равновесию. Двуокись углерода сублимируется в колбе (3). Затем закрывают кран $\mathrm{K}_{4}$, открывают медленно кран $\mathrm{K}_{1}$ и снимают колбу (1) со шлифа L.

Восстановление двуокиси углерода раствором литий-алюминий гидрила проводят непосредственно после вакуумной сублимации (см. фиг, 2).

Из системы откачивают воздух при открытых кранах $\mathrm{K}_{\mathrm{t}}$ и $\mathrm{K}_{4}$; кран $\mathrm{K}_{2}$ закрыг. Не включая насос, закрывают кран $\mathrm{K}_{4}$. Присоединяют к шлифу L гри помощи вакуумного шланга и шлиф-муфты трехлитровую термостойкую колбу (5) с восстанавливающим раствором *, которую ставят на ледяную баню (6). Далее открывают осторожно кран $\mathrm{K}_{2}$ и закрывают его при закипании восстанавливающего раствора. Закрывают кран $K_{1}$, открывают - $K_{2}$ и отмечают по манометру (4) давление паров растворителя восстанавливающего раствора. Закрывают кран $\mathrm{K}_{2}$, открывают - $K_{1}$ и, по достижении минимального давления в системе,

* Согласно уравнению требуется на восстановление 1 моли двуокиси углерода 0,75 моли литий-алюминий гидрида. Для увеличения выхода сннтеза желательно применять некоторый избыток литий-алюминий гидрида.

Требуемое количество растертого литий-алюминий гидрида растворяют в 1,2 л абсолютного н-дибутилового эфира. Так как литий-алюминий гидрида в н-дибутиловом эфире растворяется при $25^{\circ} \mathrm{C} 2$ г на 100 г растворителя (Мичович, Михайлович, 1957), получают суспензию, которую и используют в качестве восстанавливающего раствора. Полученный раствор защищают от воздействия влаги и двуокиси углерода. 
закрывают кран $\mathrm{K}_{1}$ и выключают насос. Восстанавливающий раствор взбалтывают, удаляют из-под колбы (3) Дюар с жидким кислородом и, после того, когда давление в системе достигнет значения давления паров растворителя восстанавливающего раствора, открывают кран $\mathrm{K}_{4}$. Колбу с восстанавливающим раствором следует время от времени взбалтывать в течение всего процесса восстановления.

Алкоголиз литий-алюминий метилата. На следующий день после восстановления двуокиси углерода колбу (5) отделяют от вакуумной системы (открывают кран $\mathrm{K}_{1}$, соединенный с резервуаром азота, фиг. 2), ставят на ледяную баню и алкоголизируют литий-алюминий метилат, вливая в колбу 800 мл бензилового спирта. Бензиловый спирт следует в начале алкоголиза добавлять маленькими порциями, хорошо взбалтывая реакционную смесь в колбе. Колбу закрывают пробкой, снабженной трубкой с хлористым кальцием.

Выделение метанола. Метанол выделяют из реакционной смеси путем дистилляции. Колбу (5) снабжают маленьким дефлегматором и присоединяют нисходящий холодильник. Приемник, на $70-100$ мл, присоединяют к холодильнику при помощи алонжа с отводом, соединенным с трубкой с хлористым кальцием. Затем нагревают колбу на электроплитке с закрытой спиралью, повышая при помощи автотрансформатора постепенно температуру плитки до температуры кипения реакционной смеси. Собирают фракцию с температурой кипения до $120^{\circ} \mathrm{C}$.

Дальнейшую очистку метанола ведут путем фракционированной дистилляции с хорошо действующей колонкой.

Выход метанола по двуокиси углерода составляет в среднем $50 \%$.

При описанном синтезе должны применяться соответствующие меры предосторожности против пожара и взрыва.

\section{Л И ТЕРА Т У Р А}

Мичович B., Михайлович $M$ и, 1957. Алюмогидрид лития и его применение в органической химии. $M$.

Cox J.D., Turner H. S., W arne R.J., 1950. Syntheses with isotopic tracer elements. J. Chem. Soc.

Delaney C. F. G., McAulay I. R., 1959. A radiocarbon dating system using scintillation techniques. Proc. Roy. Soc. Dublin, Al.

L i iv a A., 1959. Radioaktiivse süsiniku meetod looduslike objektide vanuse määramiseks. Eesti Loodus, nr. 3.

Li iva A., Soovik T., 1961. Absoluutse vanuse määramise esimesi kogemusi radioaktiivse süsiniku $\left(\mathrm{C}^{14}\right)$ meetodil Eestis. ENSV TA Geoloogia Instituudi Uurimused VII.

Nystrom R. F., Y a n k o W. H., B r own W. G., 1948. Reduction of carbon dioxide to methanol by lithium aluminium hydride. J. Amer. Chem. Soc., 70.

Pringle R. W., Turchinetz W., Funt. B. L., 1955. Liquid scintillation techniques for radiocarbon dating. Rev. Scient. Instrum., 26. 


\title{
METANOOLI SUNTEES LOODUSLIKU RADIOAKTIIVSE SUSINIKU MÄARAMISEKS STSINTILLATSIOONIMEETODIL
}

\author{
A. Liiva, E. Ilves
}

\section{Resümee}

Käesolevas töös tutvustatakse ENSV TA Zooloogia ja Botaanika Instituudi geobiokeemia laboratooriumis metanooli sünteesimiseks juurutatud metoodikat ja aparatuuri. Sünteesitud metanooli kasutatakse absoluutse vanuse määramiseks stsintillatsioonimeetodil.

Süntees koosneb järgmistest etappidest:

1) proovi ettevalmistamine;

2) süsihappegaasi eraldamine proovist;

3) eraldatud süsihappegaasi puhastamine vaakuumsublimatsioonil;

4) puhastatud süsihappegaasi taandamine liitiumalumiiniumhüdriidilahusega (n-dibutüüleetris) liitiumalumiiniummetülaadiks;

5) liitiumalumiiniummetülaadi alkoholüüs bensüülalkoholiga;

6) metanooli eraldamine reaktsioonisegust ja puhastamine fraktsioneeriva destillatsiooniga.

Metanooli keskmine saagis oli süsihappegaasi järgi $50 \%$.

\section{METHANOLSYNTHESE ZUR BESTIMMUNG DES NATURRADIO- KOHLENSTOFFES MITTELS DER SZINTILLATIONSMETHODE}

\author{
A. Liiva, E. Ilves \\ Zusammenfassung
}

In vorliegender Arbeit wird die im Institut für Zoologie und Botanik der Akademie der Wissenschaften der Estnischen SSR eingeführte Methodik der Methanolsynthese beschrieben.

Das aus verschiedenen kohlenstoffhaltigen Proben synthetisierte Methanol wird zur Altersbestimmung dieser Proben mittels der Szintillationsmethode verwendet.

Die Synthese besteht aus folgenden Etappen:

1) Vorbereitung der Probe;

2) Gewinnung des Kohlendioxyds aus der Probe;

3) Reinigung des gewonnenen Kohlendioxyds durch Vakuumsublimation;

4) Reduzierung des Kohlendioxyds durch eine Lösung von Lithiumaluminiumhydrid in Buthyläther zum Lithiumaluminiummethylat;

5) Alkoholyse des Lithiumaluminiummethylats mittels Benzylalkohol;

6) Gewinnung des Methanols aus der Reaktionsmischung und deren Reinigung durch fraktionierende Destillation.

Die Durchschnittsausbeute des synthetisierten Methanols auf Kohlendioxyd berechnet beträgt $50^{\circ} \%$.

Institut für Zoologie und Botanik

der Akademie der Wissenschaften der Estnischen SSR
Eingegangen am 29. Jan, 1962 